\title{
Mathematics-for-teaching: Insights from the case of annuities
}

\begin{abstract}
Author:
Craig Pournara ${ }^{1}$

Affiliation:

${ }^{1}$ Wits School of Education, University of Witwatersrand, South Africa

Correspondence to: Craig Pournara

Email:

craig.pournara@wits.ac.za

Postal address:

Box 1531, Pinegowrie 2013, South Africa

Dates:

Received: 05 Dec. 2013

Accepted: 29 Aug. 2014

Published: 14 Nov. 2014

How to cite this article: Pournara, C. (2014). Mathematics-for-teaching: Insights from the case annuities. Pythagoras, 35(1), Art. \#250, 12 pages. http://dx.doi.org/10.4102/ pythagoras.v35i1.250
\end{abstract}

\section{Copyright:}

(C) 2014. The Authors.

Licensee: AOSIS OpenJournals. This work

is licensed under the Creative Commons Attribution License.
Shulman's notations of subject matter knowledge (SMK) and pedagogical content knowledge (PCK) have been very influential in education research on teachers' knowledge for teaching. However, there is little empirical evidence in support of these as separate analytical constructs. Furthermore, attempts to distinguish SMK and PCK highlight the complex and multidimensional nature of teachers' knowledge and hence the difficulty of separating SMK and PCK. The author adopts the notion of mathematics-for-teaching (MfT) and argues that teachers' knowledge for teaching annuities comprises knowledge of mathematical aspects, knowledge of pedagogical aspects and contextual knowledge of finance. Drawing from a larger study in which the author taught a financial mathematics course to pre-service secondary mathematics teachers, four examples of teachers' knowledge for teaching annuities are identified, each of which illustrates how knowledge of mathematics, knowledge of pedagogy and contextual knowledge of finance are intertwined.

\section{Introduction}

The first time I taught annuities, it was to a group of pre-service secondary mathematics teachers. Being a novice to financial mathematics I drew heavily on the content, presentation and sequencing of available texts (e.g. Kitto et al., 1990; Young, 1993). My attention was taken up by making sense of the mathematics and its relationship to the world of finance, so I was unable to pay much attention to the students and their learning. Since that initial experience more than 10 years ago, I have taught annuities several times. Each time I have become increasingly aware of the students, their interpretations of the mathematical ideas and their difficulties. This heightened awareness of the students and their learning has forced me to think more deeply about the concept of annuities and the knowledge needed to support university students and learners in schools to engage more meaningfully with annuities, going beyond definitions and calculations. Ultimately this led to a study of teachers' mathematical knowledge for teaching of financial mathematics (Pournara, 2013a).

In this article I elaborate four instances of mathematical knowledge for teaching annuities. I show how these involve mathematical knowledge, pedagogical knowledge and contextual knowledge of finance. I argue that this knowledge is not the substance of typical financial mathematics courses in commerce or actuarial science programmes, but that is it specialised knowledge that teachers require for teaching. In so doing, I challenge the simplistic distinctions between content knowledge and pedagogical content knowledge.

The ideas presented here draw on data from a larger study of pre-service secondary mathematics teacher education in which I taught a course in financial mathematics to a group of 3rd year and 4th year Bachelor of Education students (Pournara, 2013a). The course was specifically designed for teachers and adopted an investigative approach to studying annuities. For example, students engaged with realistic financial tasks in order to derive the annuities formulae. In analysing students' responses to tasks, I was forced to consider more deeply my own conceptions of annuities. In the absence of an adequate literature base on conceptions of annuities, I had to consider from scratch questions like: 'what does it take to learn annuities?', 'what difficulties do students experience in making sense of annuities?' and 'what knowledge do teachers need to teach annuities?'

Teachers' knowledge for teaching cannot be separated from the curriculum they will teach. In the South African school curriculum for Mathematics (Department of Basic Education, 2011; Department of Education, 2003) annuities are treated as an application of geometric series and therefore only introduced at Grade 12 level, once the topic of sequences and series has been completed. Consequently, there is little time for investigative approaches in the rush to complete the syllabus for the final year of schooling. Furthermore, financial mathematics is a small section of the curriculum, being allocated only $7 \%$ of teaching time and approximately $6 \%$ of the marks 
in Grade 12 national assessments. These constraints cannot be ignored in a discussion of the knowledge teachers need to teach annuities. However, my concern here is with teachers' knowledge of annuities that will enable them to support learners to make sense of annuities in relation to the underlying mathematics and in relation to the realities of finance. In the next section I locate my perspective on teachers' knowledge within the existing literature on teachers' mathematical knowledge for teaching.

\section{Teachers' mathematical knowledge for teaching}

The rise in interest in teachers' subject matter knowledge can be linked to Shulman's $(1986,1987)$ seminal work in which he argues to re-insert knowledge of subject matter as a key component of teacher's professional knowledge and to distinguish knowledge of the discipline from the knowledge required to transform that disciplinary knowledge for teaching. By distinguishing content knowledge (CK) or subject matter knowledge (SMK) from pedagogical content knowledge (PCK), he seeks to highlight two key elements of knowledge for teaching. Ball, Thames and Phelps (2008) report that there has been unprecedented take-up of the notion of PCK since the mid-eighties. For example, they count that in 2008 the abovementioned articles by Shulman had been cited in more than 1200 refereed journal articles across 125 journals spread over a wide range of disciplines. However, they argue that the notion of PCK has remained underdeveloped and its usefulness has been hampered because it lacks clear definition and has little empirical foundation. Ruthven (2011) suggests that Shulman's taxonomy as well as the variations on the taxonomy that have followed (including Ball's work) 'have mesmerised the field rather at the expense of the model of pedagogical reasoning that accompanied earlier accounts of the taxonomy' (p. 86, italics mine).

Many in the mathematics education research community have been substantially influenced by Shulman's ideas. For example, adopting the SMK-PCK distinction, Even $(1990,1993)$ elaborates a conception of SMK, with particular focus on functions, and proposes seven aspects of teachers' SMK. However, Huillet (2009) argues that four of Even's aspects blur the boundary between SMK and PCK. For example, she argues that the categories different representations and basic repertoire of key tasks and examples both relate to teaching practice and therefore inevitably involve PCK as well as SMK. In their attempt to extend Shulman's work, Ball and her colleagues in the United States of America (Ball, Hill \& Bass, 2005; Ball et al., 2008) propose additional subconstructs within SMK and PCK. Through a programme of extensive empirical research they have sought to provide evidence for the existence of some of these constructs and to measure teachers' knowledge in relation to the constructs (e.g. Hill, Ball \& Schilling, 2008; Hill, Rowan \& Ball, 2005). However, to date their findings provide only limited evidence for distinguishing specialised content knowledge (SCK) and knowledge of content and students (KCS). The COACTIV group working in Germany (e.g. Krauss, Baumert \& Blum, 2008;
Krauss et al., 2008) distinguished CK and PCK empirically through tests of teachers' knowledge. However, their ability to distinguish the constructs is highly dependent on their definitions of the two constructs. They define CK as advanced background knowledge of school mathematics, which goes beyond the requirements of the curriculum and enables the teacher 'to cope with mathematically challenging situations' (Krauss, Baumert \& Blum, 2008, p. 54). PCK is defined as knowledge of explanations and representations, knowledge of students' difficulties and errors and knowledge of multiple solutions to tasks. These definitions provide a 'safe zone' between CK and PCK in that specialised knowledge relating to the core mathematical aspects of the curriculum is not included in either category. Ball et al. (2008) argue that it is frequently difficult to distinguish clearly between SCK and KCS. They cite the example of selecting tasks to test learners' understanding of decimals, which involves both SCK (drawing on the key mathematical ideas to produce a list of decimals to be ordered) and KCS (to consider examples that would give learners particular difficulty). The COACTIV group avoid this blurring: whilst their definition of PCK includes knowledge of learners' difficulties, they appear to ignore knowledge of the key mathematical ideas in their definition of CK since the key ideas would not be considered advanced knowledge.

Given the difficulties in establishing productive yet clear boundaries between knowledge categories, and in producing empirical evidence for the existence of the proposed categories, I choose to avoid the SMK-PCK conundrum. I choose the term mathematics-for-teaching (MfT) following Adler (2005) and Adler and Davis (2006) to refer to teachers' knowledge for teaching mathematics. I concur with many others in the field (e.g. Ball, Bass, \& Hill, 2004; Ball et al., 2008; Even, 1990, 1993; Ferrini-Mundy, Floden, McCrory, Burril \& Sandow, 2006; Huillet, 2007, 2009) that teachers' mathematical knowledge is complex and topic specific. I consider MfT as an amalgam of SMK and PCK, in which fine distinctions between mathematical and pedagogical aspects are not a priority.

In the context of mathematical knowledge for teaching financial mathematics, I propose three knowledge clusters:

- Aspects that are mainly mathematical - knowledge of essential features of a concept (Even, 1990), different ways of approaching the concept (Even, 1990, 1998), the relationship of the concept or topic to other areas of mathematics, applications and modelling and broader mathematical practices such as defining, conjecturing, exemplifying and proving.

- Aspects that are mainly pedagogical - knowledge of a basic repertoire of key tasks and examples (Even, 1990), different teaching sequences and approaches (Ferrini-Mundy et al., 2006), explanations and learners' conceptions.

- Aspects of contextual knowledge of finance - financial concepts and conventions, socioeconomic issues and financial literacy. It is this cluster of knowledge that 
provides insights into MfT, which may not be visible when one focuses on areas such as algebra, calculus or geometry.

In this article I focus on four examples of teachers' knowledge for teaching annuities and argue that each illustrates why hard distinctions between SMK and PCK are unhelpful. In one sense these may each be considered as examples of SCK, yet each has the learner in sight at all times, so in Adler and Davis's (2006) terms they would be considered Mt (primary focus on mathematics with secondary focus on teaching and pedagogy). The first example involves an expanded view of the compound interest formula, in which I argue that teachers are required to integrate knowledge of the formula, knowledge of learners' conceptions of it and knowledge of how the formula is viewed in financial contexts beyond school. The second example deals with two different approaches to learning annuities. Here I show how knowledge of mathematics, the curriculum and learners' conceptions are intertwined. The third example concerns modelling of time in annuities scenarios and shows how knowledge of mathematical modelling, finance and students' conceptions intersect. The final example involves different interpretations of the exponent in financial mathematics formulae. This example shows powerfully how knowledge of mathematics and learner conceptions intersect and challenges even the 'distant definitions' of CK and PCK adopted in the COACTIV work. These four issues are unlikely to be dealt with in a typical financial mathematics course in commerce or actuarial science programmes, yet they constitute important knowledge for teachers and hence exemplify specialist mathematical knowledge for teaching annuities.

In the next section I provide a brief review of the limited research literature on conceptions of annuities. Thereafter I propose a hierarchy of concepts related to annuities to provide a backdrop for the later discussion about elements of teachers' knowledge for teaching annuities.

\section{Research on conceptions of annuities}

Little research has been published on students' conceptions of annuities at school or university level. Some work has been published on approaches to teaching annuities to university students (e.g. Dempsey, 2003; Eddy \& Swanson, 1996; Gardner, 2004; Jalbert, Jalbert \& Chan, 2004) but, with the exception of Dempsey (2003), these are largely anecdotal. The work by Hoyles, Noss and their colleagues (e.g. Bakker, Kent, Noss, Hoyles \& Bhinder, 2006; Hoyles, Noss, Kent \& Bakker, 2010) provides the only research-based evidence on thinking about annuities.

As part of their study on techno-mathematical literacies in the workplace, Hoyles et al. (2010) focused on two pension companies and a mortgage company in the United Kingdom, all dealing with annuities-based scenarios. They identified several gaps in the knowledge of sales and service employees, including inadequate understanding of the growth of money and the notion of present value of money and of the key variables and their relationships in mortgage scenarios. They also noted a lack of appreciation of the mathematical models that underpin the documents produced by the IT system, such as pension statements, and poor ability to interpret visual representations. Employees were also unable to make estimates and predictions of costs for individual customers. Since employees lacked this knowledge, they were unable to help customers with simple comparisons such as comparing the monthly interest rate charged on customers' credit cards (say 1.9\%) with the annual mortgage loan rate being offered (which was approximately $6 \%$ p.a.).

\section{A hierarchy of annuities concepts}

Given the lack of research on annuities, it has been necessary to develop a hierarchical network of links between key concepts relating to annuities in order to provide a reference point from which to undertake my own research. This network builds on a theoretical elaboration of compound interest that includes a hierarchy of interest concepts and a network of concepts related to growth factor (Pournara, 2013b). The network proposed in Figure 1 was developed with an eye on the requirements of the school curriculum. Concepts that are higher up in the diagram build on those that are lower down. In the discussion below I use italics to identify the nodes in the diagram.

The notion of the time value of money underpins all aspects of annuities. Time value is based on the principle that an amount of money is worth more today than the same amount of money in the future because it has potential to earn interest. The operation of compounding and its reverse, the operation of discounting, provide the mechanisms by which an amount is moved forwards or backwards in time. This is operationalised by multiplying the present value, or dividing the future value, by the unit growth factor $(1+i)$. (See Pournara [2013b] for a discussion of growth factor and unit growth factor.)

In Figure 1, the operations of compounding and discounting are linked to present value and future value of single payments respectively and then to multiple payments in the four annuities scenarios. In locating multiple payments in Figure 1, I begin with simple annuities where the frequency of payments corresponds with the frequency of compounding interest. Here I include future value of ordinary annuity, future value of annuity due, present value of ordinary annuity and present value of annuity due, thus distinguishing payments in advance (annuity due) from payment in arrears (ordinary annuity) for both present value and future value. I include sinking funds and outstanding balance since they are included in the Grade 12 curriculum. I refer here only to sinking funds that involve setting up a fund to make provision for the replacement of an asset at some time in the future, since this is the scope of sinking funds studied at school level.

Future value of an annuity is linked to sinking funds because it is used to determine the value of the regular payments 


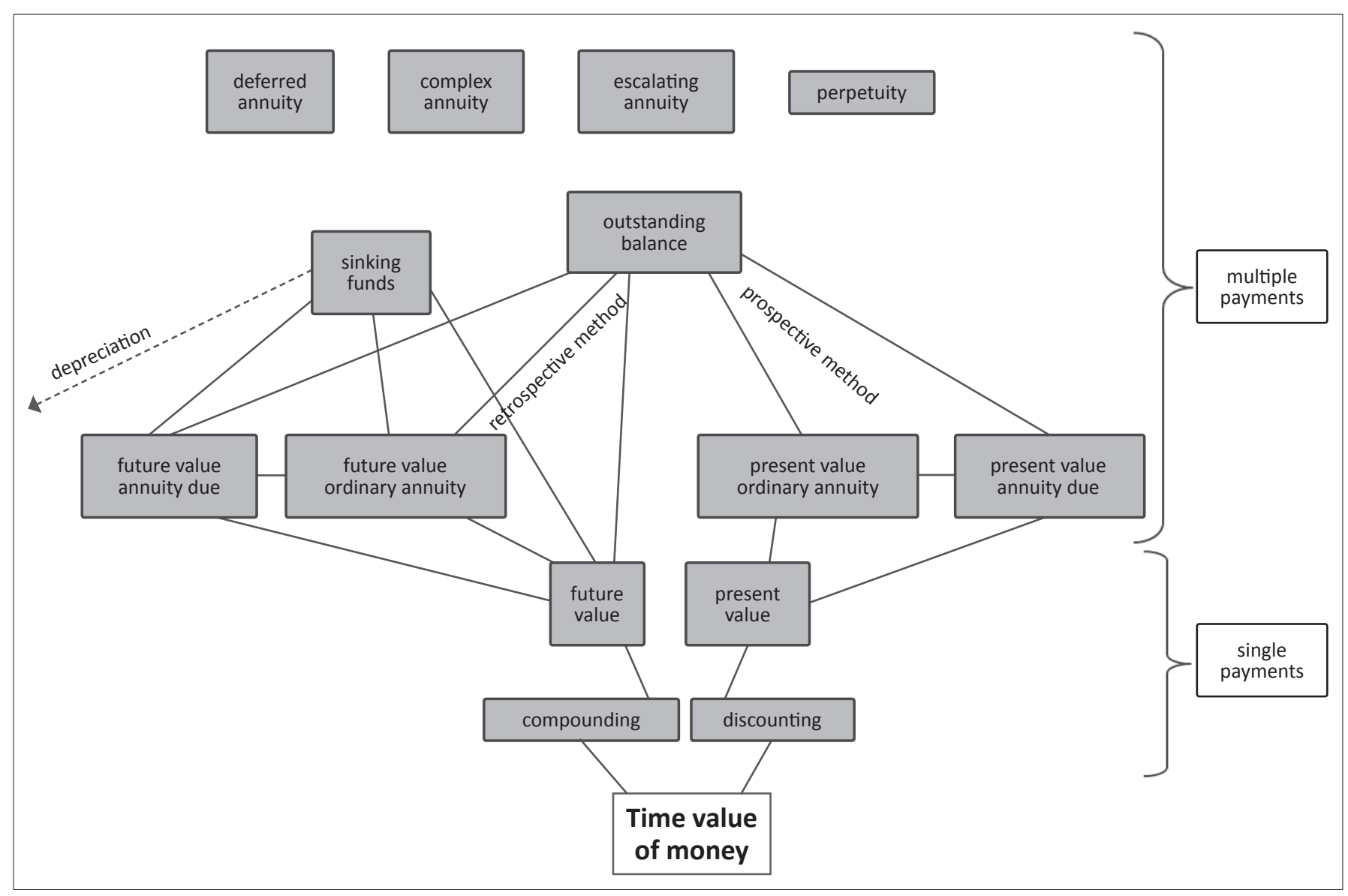

FIGURE 1: A hierarchy of annuities concepts.

at some point in the future when the new asset will be purchased. Similarly, future value (of a single payment) is linked to sinking funds because it determines the depreciated value of the asset that will be replaced. For this reason, a link with depreciation is also indicated. This links to Figure 1 in Pournara (2013b).

Figure 1 shows how outstanding balance draws together several concepts from lower levels. The outstanding balance at some time $T_{k}$ can be calculated in two ways. In the retrospective method the loan is moved forward to $T_{k^{\prime}}$ thus calculating the interest on the loan at $T_{k}$ as if no repayments have been made. Each of the $k$ repayments is also moved forward to $T_{k}$ and the outstanding balance is the difference between the future value of the loan amount and the sum of the future values of each repayment, as given by the formula:

Outstanding balance $=\operatorname{Loan}(1+i)^{k}-$ pymt $\frac{(1+i)^{k}-1}{i}$

In Figure 1, the link from future value (of a single payment) indicates the loan and the links from future value of annuity indicate the $k$ repayments.

In the prospective method the outstanding balance at some time $T_{k}$ is the sum of the present values of all the repayments that have not yet been made. The outstanding payments are therefore moved back in time to $T_{k}$ as shown by the formula: Outstanding balance $=$ pymt $\frac{1-(1+i)^{-m}}{i}$, where $m$ is the number of outstanding payments. This is reflected by the links between present value of annuity and outstanding balance.

The concepts of deferred annuity, complex annuity, escalating annuity and perpetuity are included for completeness. Although deferred annuity is not specifically mentioned in the curriculum, it is possible to include it at Grade 12 level since it only requires a simple adjustment for time. The other three annuity concepts are beyond the scope of the Grade 12 curriculum.

\section{An expanded view of the compound interest formula}

In this section I distinguish two views of the compound interest formula and argue that learners should be able to adopt either view as appropriate. Knowledge of these two views is specialised knowledge for teachers and would likely not be encountered in a typical financial mathematics course, and certainly not in current school texts. I offer this as an example of MfT that draws on knowledge of mathematics, curriculum and tasks, and thus the intersection of SMK and PCK.

Learners are typically introduced to the compound interest formula in Grade 9 or Grade 10 to determine the accumulated value of a certain amount over a period of time. Whilst this is 
a necessary and important use of the formula, it is inadequate for developing a full grasp of annuities. I therefore propose the need for an expanded view of the compound interest formula, similar to Kieran's (1981) call for an expanded view of the equal sign. In the same way that learners must be able to view the equal sign as both a do-something operator and as an equivalence relation, so they need to view the compound interest formula from both an accumulation and an adjustment perspective as elaborated below.

The accumulation view is a static view, best exemplified in questions of the form: an amount, $P$, is invested at a certain rate, $r$, compounded monthly for a certain period, $n$, and we want to determine $A$, the amount that accumulates. Thus we have the general form $A=P(1+r)^{n}$, although this will need to be adjusted for monthly compounding. Here we focus on the original amount and then on the final amount, and compare (in an additive sense) the amount by which the original has changed because this tells us how much interest has accumulated. We are only interested in the magnitude of $A$, not in its relative value in relation to the passage of time or corresponding changes in its buying power. The dominant message is that the principal amount accumulates interest and becomes 'more'. The focus is thus on the nominal value of the principal amount, which is separated from time.

The adjustment view focuses on the time value of money. It is a dynamic view in which we are interested in adjusting for the effects of time or, more correctly, the effects of inflation, exchange rates, and so on. So, we are concerned with the value of an amount at different points in time; we can use the compound interest formula as a mechanism to move our amount of money to different points in time along a timeline. It is therefore associated with compounding and discounting. Here it may be better to refer to present value (rather than principal) and future value (rather an accumulated amount); thus, we may represent the general formula as: $F V=P V(1+i)^{\mathrm{n}}$. From an adjustment point of view, we are less interested in the actual magnitude of the number and more concerned with its relative value at a different point in time. In real terms, the new amount may not have a higher value than the principal amount had in the past, although in nominal terms the new amount is 'more' because it is a larger number. But since the time value of money is linked to its buying power, the magnitude of the number must always be seen in relation to what it can buy, such as groceries or foreign currency.

The accumulation view is emphasised throughout the school curriculum. Typical questions require learners to solve for an unknown in the compound interest formula and the focus is generally on the difference between the initial and final amounts, even when learners are required to calculate the time period of the investment. However, when dealing with annuities, the compound interest formula needs to be viewed as an adjustment mechanism because the individual payments are being moved forwards or backwards in time to determine their contribution to a loan, outstanding balance or projected savings. Unfortunately, since annuities are only introduced in Grade 12, the need for an expanded view of the formula comes very late. Nevertheless, based on discussions with actuaries working in the financial sector and in academia, the adjustment view is the one that they use most often and that is captured in typical statements such as 'discounting a payment back to $T_{0}$ ' (i.e. the point at which a loan is taken or an annuity is purchased). This suggests that the prevalent view of the compound interest formula in school mathematics does not reflect its dominant use in the banking sector and in actuarial science. This is likely a consequence of an overemphasis on basic interest calculations for several years of schooling, an underemphasis on annuities and little attention to the notion of the time value of money.

Helping learners to view the compound interest formula in multiple ways is a teacher's responsibility akin to supporting younger learners to see the equal sign as both a do-something signal and an equivalence relation. In both situations the teacher draws on knowledge of mathematics and of the ways in which the curriculum has already impacted learners' conceptions. It is through the design and mediation of appropriate tasks that learners may be pushed to think about the formula in different ways. Awareness of the emphasis on an adjustment view in the financial sector and in more advanced financial mathematics may provide additional motivation for the need to expand learners' views of the formula.

\section{Two approaches to annuities}

Even (1990) identifies knowledge of alternate ways of approaching a concept as an aspect of SMK. In this section I describe two different ways of approaching annuities based on the pre-service teachers' initial engagement with annuities tasks. As with different views of the compound interest formula described above, knowledge of different ways of approaching annuities is important for teachers although it is likely that others working with financial mathematics are also aware of both approaches. However, teachers require knowledge of how the two approaches differ and how they intersect, which goes beyond an awareness of their existence.

Textbooks typically introduce annuities problems as applications of geometric progressions. However, data from my study suggest that when students first encounter annuity-based tasks, and are left to devise their own strategies, they do not necessarily focus on each payment and make use of a geometric progression. Rather, they track the account balance over time. From this observation I distinguish two different approaches to working with annuity situations. The first approach I call an account balance $(\mathrm{AB})$ approach because it focuses on tracking the account balance. This approach mirrors what goes on in the bank each month (although the detail of daily interest calculations is ignored). In the case of annuity-based savings, a deposit is made, it is added to the account balance, interest accumulates and the closing balance is 
calculated at the end of each month. In the case of a loan, the loan is granted, then interest accumulates for the first month, a repayment is made and deducted from the capital balance; this process is repeated until the loan is repaid. This approach is easy to make sense of and, in my experience, is the approach students adopt when initially attempting to model an annuity-based scenario. The unit of analysis is account balance against time. It depends on simple iterative calculations, but when there is a departure from the perfect payment plan, all balances need to be recalculated, which makes it an inefficient and cumbersome approach.

The second approach focuses on the behaviour of each individual payment over time, so I refer to it as an individual payment (IP) approach. In this approach each payment is disaggregated from the whole and its contribution to the overall balance is modelled by moving it forward (or backward) in time by means of compound interest calculations. In the case of an investment, each deposit is moved forward to the end of the investment period so one can see the contribution it makes to the final amount. In the case of a loan, each payment is moved back to the point when the loan is granted. The unit of analysis for the IP approach is individual payment against time.

The IP approach does not reflect the monthly process of making payments and gaining interest. Rather, it is an analytical approach that projects the growth of money into the future (or back to $\mathrm{T}_{0}$ ). It is mathematically more powerful than the $\mathrm{AB}$ approach as it draws on geometric progressions, which reflect the underlying mathematical structure of annuity-based scenarios. It is also a more efficient approach: when there is a departure from the perfect payment plan, only the changed payments need to be considered when recalculating balances. For both these reasons, it is not surprising that mathematics textbooks adopt this approach from the outset.

It is important for teachers to recognise the differences in these two approaches and to be aware that learners may not initially appreciate the elegance of an IP approach, despite its prevalence in textbooks. I now move to discuss the derivation of the formula for future value of an annuity due using both approaches. In so doing, I draw on data from the study and show how the different approaches and their associated logic converge on the same algebraic formulation but with different interpretations of the algebraic forms.

\section{Deriving a formula for future value of annuity due using an account balance approach}

As noted above, the $\mathrm{AB}$ approach broadly models what happens in banks on a monthly basis. In order to make sense of the real-world problem, students need to understand how this works. By doing the iterative calculations for a few months, they see the patterns modelled by the calculations. From this inductive process it is possible to derive the annuities formulae as shown in Figure 2, which provides general expressions for the calculations that are done at the end of every period.

In Figure 2, each row (lines 1 to 6) represents a period. The middle column indicates that payment is made at the beginning of the period and that interest is gained at the end of the period. The right-hand column gives the strategically factorised expression. I call it 'strategically' factorised because it is possible (and tempting) to expand the expressions in the square bracket and then collect like terms, which may or may not lead to some form of factorisation. The factorised form shown below preserves the unit growth factor $(1+i)$, which ultimately produces the geometric series. In the middle column, the factor $(1+i)$ is multiplied by each term in the 'expanding bracket'. Thus, in each line the expression in the square bracket expands but the emerging pattern in exponents is easily seen.

Obviously a strategic substitution of $k=1+i$ would substantially improve the readability of the expressions and also show more clearly the geometric progression embedded in the expanding expression. In order to move from this form to the standard formula for future value of annuity due students can do one of two things: either they must recognise the geometric progression (which may or may not include common factors), identify the first term, common ratio and then substitute appropriately into the formula for the sum of a geometric progression, or they must use the elimination method to remove all 'middle' terms and then complete the necessary algebraic manipulation.

However, the elegance of the expressions above may not be easily visible in the struggle to derive the formula. For

\begin{tabular}{|ccll|}
\hline Line & $\begin{array}{r}\text { End of } \\
\text { period }\end{array}$ & $\begin{array}{l}\text { Expression for process of making new } \\
\text { payment and gaining interest }\end{array}$ & Strategically factorised expression \\
\hline 1 & 1 & $F V_{1}=P+P i$ & $F V_{1}=P[1+i]$ \\
2 & 2 & $F V_{2}=(P[1+i]+P)(1+i)$ & $F V_{2}=P\left[(1+i)^{2}+(1+i)\right]$ \\
3 & 3 & $F V_{3}=\left(P\left[(1+i)^{2}+(1+i)\right]+P\right)(1+i)$ & $F V_{3}=P\left[(1+i)^{3}+(1+i)^{2}+(1+i)\right]$ \\
4 & 4 & $F V_{4}=\left(P\left[(1+i)^{3}+(1+i)^{2}+(1+i)\right]+P\right)(1+i)$ & $F V_{4}=P\left[(1+i)^{4}+(1+i)^{3}+(1+i)^{2}+(1+i)\right]$ \\
5 & $\ldots$ & & \\
6 & $n$ & $F V_{n}=\left(P\left[(1+i)^{n-1}+\ldots+(1+i)^{3}+(1+i)^{2}+(1+i)\right]+P\right)(1+i)$ & $F V_{n}=\left(P\left[(1+i)^{n-1}+\ldots+(1+i)^{3}+(1+i)^{2}+(1+i)\right]+P\right)(1+i)$ \\
\hline
\end{tabular}

FIGURE 2: Account balance approach to generate series for future value of annuity due. 
example, in Figure 3, I show student Hailey's first attempt to derive this formula using an $\mathrm{AB}$ approach.

Hailey has compressed many lines of algebraic manipulation into this summary. She notes the common factor of $P(1+i)$, then the patterns in the highest two powers of the exponent and the constant, and she refers to the remaining terms as 'some other stuff'. She describes this as 'a sort of general pattern'. The structures she identifies do not lead her to the required expression and, even if they had, her approach does not reflect the thinking that will be most useful in working with annuity-based problems. Rather, she needs to shift to an IP approach since the AB approach is limited in providing a useful and flexible model to deal with annuitybased scenarios.

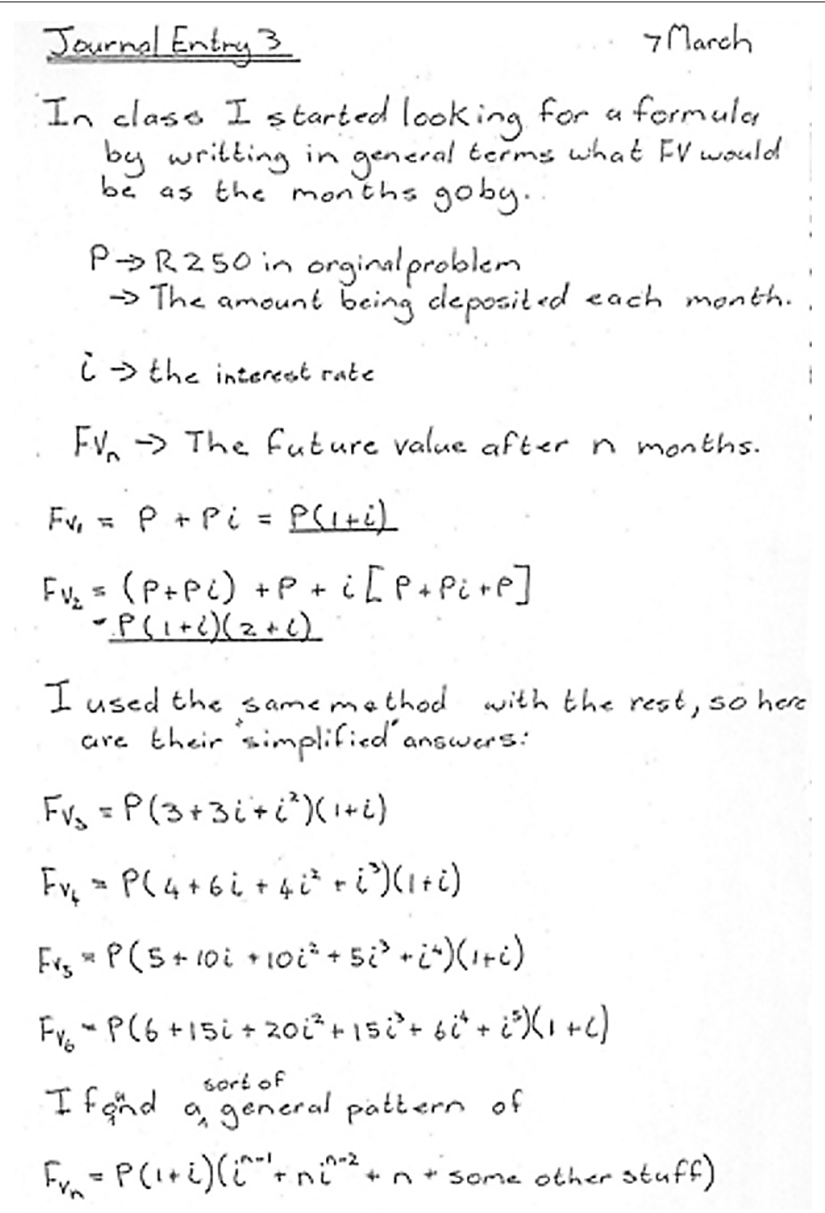

FIGURE 3: Hailey's attempt to simplify algebraic expressions for future value of annuity.

\section{Deriving a formula for future value of annuity due using an individual payment approach}

Figure 4 shows the elegance of the IP approach for the future value of an annuity due, assuming 12 equal monthly payments. Here each row (from line 1 to 6) represents the future value of a particular payment at the end of period 12 . The terms generated are clearly recognisable as those of a geometric progression.

Whilst this method produces the same final result as the $A B$ approach, the underlying thinking is substantially different. This approach does not model the monthly process in the bank. Each payment requires one to run through the timeframe from the point at which the payment is made to the end of the investment. As with the $\mathrm{AB}$ approach, in order to move from this form to the standard formula for future value of annuity due, students must either apply the formula for a geometric series or use the elimination method coupled with the necessary algebraic manipulation.

Evidence from the study suggests that the IP approach is not intuitive (Fischbein, 1999), and does not appear to be the obvious starting point for many students. It requires a substantial shift in thinking to conceive of an annuity situation in this way. However, once this shift is made, students appear to have little difficulty in adopting an IP approach. This finding thus challenges the starting point adopted by most textbooks in introducing annuities. Whilst clearly indicating that there are different ways of approaching annuities, it also suggests at least two different teaching sequences and approaches. In their framework, Ferrini-Mundy et al. (2006) identify knowledge of different teaching sequences and approaches as an aspect that foregrounds teachers' pedagogical knowledge. By contrast, as mentioned above, Even (1990) refers to knowledge of different ways of approaching a concept. Therefore, in considering the $A B$ and IP approaches from the perspective of MfT, we see again how knowledge of mathematical and pedagogical aspects intersect and are not easily separated in terms of SMK and PCK.

\section{Dealing with a paradox in the modelling of time}

The modelling of time in annuities scenarios exemplifies the intersection of mathematical and contextual aspects of MfT of annuities. I discuss the importance of conventions in

\begin{tabular}{|c|c|c|}
\hline Line & Value of payment at end of period $12\left(T_{12}\right)$ & Strategically factorised expression \\
\hline 1 & $F V_{1}=P(1+i)^{12}$ & These terms are then added together and a common factor of $\mathrm{P}$ is factorised \\
\hline 2 & $F V_{2}=P(1+i)^{11}$ & Future value of annuity \\
\hline 3 & $F V_{3}=P(1+i)^{10}$ & $=P(1+i)^{n}+P(1+i)^{n-1}+\ldots+P(1+i)^{3}+P(1+i)^{2}+P(1+i)$ \\
\hline 4 & $\ldots$ & $=P\left[(1+i)^{n}+(1+i)^{n-1}+\ldots+(1+i)^{3}+(1+i)^{2}+(1+i)\right]$ \\
\hline 5 & $F V_{11}=P(1+i)^{2}$ & \\
\hline 6 & $F V_{12}=P(1+i)$ & \\
\hline
\end{tabular}

FIGURE 4: Individual payment approach to generate series for future value of annuity due. 
modelling time and show how these conventions overcome a paradox when payments are made at the end of the period. In the study, an appreciation of the paradox proved to be an important insight in order to make sense of what initially appeared to be students' ignoring of the timeframes specified in the task.

In the world of banking, an annuity payment can be made at any time of the month and interest is calculated daily and compounded monthly. (See Pournara [2012], for a detailed discussion of the distinction between daily interest calculations and monthly compounding.) However, mathematical models remove this complexity by considering only two scenarios: payment in advance (annuity due), where the payment is made at the beginning of the period, and payment in arrears (ordinary annuity), where payment is made at the end of the period. Furthermore, the beginning and end of the period are defined very specifically. For example, by convention a payment made at the end of a month does not gain interest in the month in which is it deposited. Without this convention, we are faced with the following paradox: if payment is made at the end of the month and interest is compounded also at the end of the month, we have one process that is dependent on another and yet both processes take place simultaneously. So, given that interest is capitalised at the end of the month, if payment is not included in this interest calculation, then one could reason that the payment must be happening after the end of the month, in other words at the beginning of the next month. Thus it might be argued that payment at the end of month $n$ is really payment at the start of month $n+1$. However, a different model is used for payment at the beginning of the month (annuity due) and so this interpretation is not acceptable. If, on the other hand, the payment is made before interest is calculated, then we may reason that the payment is not made at the end of the month. This gives rise to a subtle but crucial difficulty.

Consider the scenario in which regular monthly payments of R200 are made at an interest rate of $6 \%$ per annum compounded monthly. In Table 1 the payments are made at the beginning of the month. In Table 2 payments are made at the end of the month. The key difference between the tables is the position of the Payment column. In Table 1, Payment occurs immediately after Opening balance, thus modelling payment made at the beginning of the month. In Table 2, Payment occurs after the Interest column to indicate that the payment is made at the end of the month. The column Balance on which interest is calculated has been included to make explicit the amount of money in the account at the time of compounding interest. Given that there are only two scenarios for modelling the timing of payments, if we want to model payment at the end of the period but place Payment before Balance on which interest is calculated the result is that we model payment at the beginning of the period. This is a subtle but important distinction. We may intend to model that the payment is made just before interest is calculated but the mathematical model assumes the payment has been in the account for the full month and thus gains interest for the entire period.

The essential difference between the above situations hinges on whether the payment is added before interest is calculated. This translates to a time difference of a full period of interest on the latest payment, which shows that we cannot (easily) model 'payment just before calculating interest'. There are only two options: 'payment before', which translates to payment at the beginning of the period, and 'payment after', which translates to payments at the end of the period. Hence the need for the convention: a payment made at the end of the period does not gain interest in the month in which it is deposited. This is equivalent to thinking about the order as follows: a payment made at the end of the month takes place after the interest is capitalised for the month but before the beginning of the next month. Whilst this statement may appear contradictory, it is nevertheless a useful way of interpreting the convention for payment at the end of a period and is thus a typical example of Shulman's (1986) description of PCK as a way of 'representing and formulating the subject that make[s] it comprehensible to others' (p. 9).

It is unlikely that students or learners will recognise and appreciate the paradox unless they are given the opportunity

TABLE 1: Annuity payments made at the beginning of the month.

\begin{tabular}{|c|c|c|c|c|c|}
\hline Period & $\begin{array}{l}\text { Opening } \\
\text { balance }\end{array}$ & Payment & $\begin{array}{l}\text { Balance on which } \\
\text { interest is calculated }\end{array}$ & Interest & Capital balance \\
\hline 1 & 0.00 & 200.00 & 200.00 & 1.00 & 201.00 \\
\hline 2 & 201.00 & 200.00 & 401.00 & 2.01 & 403.01 \\
\hline 3 & 403.01 & 200.00 & 603.01 & 3.02 & 606.02 \\
\hline 4 & 606.02 & 200.00 & 806.02 & 4.03 & 810.05 \\
\hline 5 & 810.05 & 200.00 & 1010.05 & 5.05 & 1015.10 \\
\hline
\end{tabular}

TABLE 2: Annuity payments made at the end of the month.

\begin{tabular}{ccccc}
\hline Period & $\begin{array}{c}\text { Opening } \\
\text { balance }\end{array}$ & $\begin{array}{c}\text { Balance on which } \\
\text { interest is calculated }\end{array}$ & Interest & Payment \\
\hline 1 & 0.00 & 0.00 & 0.00 & 200.00 \\
2 & 200.00 & 200.00 & 1.00 & 200.00 \\
3 & 401.00 & 401.00 & 2.01 & 200.00 \\
4 & 603.01 & 603.01 & 3.02 & 200.00 \\
5 & 806.02 & 806.02 & 4.03 & 603.01 \\
\hline
\end{tabular}


to model the scenario using their own ideas and approaches. Similarly, if teachers only approach the teaching of financial mathematics by giving formulae and procedures then the issue may not emerge. In this case it may be argued that teachers do not need knowledge of the paradox. In the study, it was only through extended grappling with the students' responses (before they had learned the formulae and conventions) that I came to recognise the paradox. Initially I interpreted their responses through the lens of the annuities conventions and so assumed they had not paid attention to the instruction that payments were made at the end of the month. However, I was uneasy with this deficit interpretation of their reasoning because the 'error' was so pervasive across their responses. It was only when I recognised the paradox that I could appreciate that their models made sense to them and they were intending to model payment at end of month but their order of adding the new payment before compounding was the reverse of the convention.

In this section I have shown how contextual knowledge of finance links with mathematical knowledge and knowledge of learners' thinking in the modelling of time in financial scenarios. The modelling conventions greatly simplify the complexity of dealing with time in financial scenarios. However, students and learners who do not yet know these conventions, and thus work from an everyday understanding of banking processes, are likely to produce their own models that do not fit with convention and that may therefore be disregarded by teachers. Thus teachers' knowledge of the modelling conventions cannot be easily separated from knowledge of how someone who does not yet know the conventions might model the situation. Furthermore, this needs to be accompanied by knowledge that the models do not take into account the daily workings in the world of banking.

\section{Different interpretations of the exponent in financial formulae}

The final example concerns the meaning of the exponent in the compound interest and annuities formulae. I argue that the exponent may be interpreted in different ways. By tracing through the derivations of the formulae, I show how this arises and I thus illustrate how a deeper consideration of the mathematics is necessary to appreciate these different interpretations.

When learners are first introduced to the compound interest formula in Grade 9 or Grade 10, they are likely to view the exponent as the number of times the principal amount is compounded. Consider the following typical question:

- I invest R500 at 6\% per annum compounded monthly for 4 years. How much will I have in total at the end of the 4-year period?

The solution to this question involves substituting 48 for $n$ since there are 48 compoundings over the four-year period.
Thus $n$ represents number of times interest is compounded: $F V=500(1+0.005)^{48}$. This interpretation of $n$ arises from the use of the compound interest formula.

When learners see the expression $(1+\mathrm{i})^{n}$ in the context of an annuities formula, such as $F V=\frac{p m t\left[(1+i)^{n}-1\right]}{i}$, it seems reasonable to assume that $n$ still represents the number of compounding periods, if for no other reason than the similarity in form. However, given that there are multiple payments, each gaining interest for a different length of time, there is likely to be some concern about which number of compounding periods $n$ refers to. Consider the following question:

- I make payments of R500 into a savings account at the end of each month. Interest is $6 \%$ per annum compounded monthly. How much will I have in total at the end of 3 years?

Solving this question involves substituting 36 for $n$ in the formula for future value of an ordinary annuity since there are 36 payments in three years: $F V=500 \frac{(1+0.005)^{36}-1}{0.005}$. Here $n$ is treated as the number of payments. It does not represent the number of times the first payment gains interest because then $n=35$ since the payment does not accumulate interest in the month in which it is deposited.

Interviews with the pre-service teachers revealed that several of them were unsure about the meaning of $n$ in the annuities formulae: does $n$ represent number of compounding periods or the number of payments? I argue that the exponents may be considered to have different meanings based on the ways in which they are used in the respective formulae. I illustrate the shift in the meaning of $n$ with reference to the formula for future value of an ordinary annuity. In tracing how the compound interest formula is initially used, and then how it is used to derive the annuities formulae, I show how students' difficulties may emerge.

Consider the scenario of a single payment, $P$, gaining compound interest monthly at a monthly rate, $i$, for four months. Figure 5 shows two different expressions for the future value at the end of each month. The exponent in the right-hand column represents the number of times the principal amount has been compounded. In the simplified expression the month number, subscript and exponent all have the same value for any particular month.

A similar pattern arises when working with annuities using an $\mathrm{AB}$ approach. Consider a scenario with four equal payments, $P$, made at the end of each month with monthly compounding again at a monthly rate, $i$. Figure 6 shows that the subscript is one unit larger than the highest exponent in the factorised expression. This reinforces the association of $n$ with number of compoundings because at the end of each month interest is compounded on the balance. Of course $n$ also indicates the number of terms within the square bracket of the strategically factorised expression, but this may be less obvious than the relationship between the subscript and the highest exponent. 
Now consider the same annuities scenario with an IP approach. Figure 7 indicates the accumulating interest on all four payments separately. Each line represents the future value of a single payment at $\mathrm{T}_{4}$. All four payments are then combined to determine the future value of the annuity $\left(\mathrm{FV}_{\mathrm{ann}}\right)$ at the end of month 4 . This is the point at which the fourth payment is made; hence it does not accumulate any interest.

There is a subtle shift in the meaning of the exponent across the three figures. In the compound interest calculations in Figure 5, the exponent represents the number of times a payment has gained interest since it was deposited. In the IP calculations in Figure 7, the exponent represents the number of times the payment will gain interest by the end of the term of the investment, in this case the end of the fourth month. Whilst the exponent refers to the number of compoundings in both cases, there is a subtle difference in what it represents. There is also a difference in the ordering of the exponents. In Figure 5 the exponents are ascending, whilst in Figure 7 they are descending. However, the sums of the four terms are equal.

In the $A B$ approach in Figure 6, the exponents represent the number of times each payment has gained interest since being deposited, as in the compound interest formula. When factorised, the resulting expression is the same as that for $\mathrm{FV}_{\mathrm{ann}}$ in Figure 7. However, the expression may be viewed differently. For example, learners may not consider the exponent to represent anything in particular; they may simply see it as the result of their algebraic manipulation.

The shift in the interpretation of $n$ comes when the annuities formulae are introduced. The formulae develop from geometric series, where each term represents the future value of an individual payment at some point $T_{n}$. Thus the expression for the future value of an ordinary annuity at $T_{n}$ is given by:

$F V_{n}=P+P(1+i)+P(1+i)^{2}+P(1+i)^{3}+\ldots+P(1+i)^{n-1}$

Each exponent represents the number of times a particular payment will gain interest by time $\mathrm{T}_{\mathrm{n}}$. Thus, $n$ still represents number of compoundings. However, once the expression is manipulated to produce the formula $F V_{n}=\frac{p m t\left[(1+i)^{n}-1\right]}{i}$, the meaning of $n$ shifts. It then represents the number of payments since the annuities formula has emerged from the formula for the $n$th partial sum of a geometric series, where $n$ represents the number of terms in the series and each term is associated with a payment: $S_{n}=\frac{a\left(r^{n}-1\right)}{r-1}$.

Ironically, even if one works from first principles to derive the annuities formulae, it may be no more convincing that $n$ represents the number of terms. The typical elimination method for an ordinary annuity is shown in Box 1 .

In lines 1 and 2 the exponents represent the number of times each payment will gain interest by time $T_{n}$. Lines 3 and 4 involve algebraic manipulation and the $n$ that remains comes from the last term in line 2. Thus $n$ is still associated with compoundings. However, in line 4 the conventional formula for future value of an ordinary annuity emerges. When we use this formula, we substitute the number of payments

\begin{tabular}{|cl|}
\hline $\begin{array}{c}\text { Payment } \\
\text { number }\end{array}$ & Value of payment at end of month $\mathbf{4}\left(\mathbf{T}_{\mathbf{4}}\right)$ \\
\hline 1 & $F V_{1}=P(1+i)^{3}$ \\
2 & $F V_{2}=P(1+i)^{2}$ \\
3 & $F V_{3}=P(1+i)$ \\
4 & $F V_{4}=P$ \\
& $F V_{a n n}=P(1+i)^{3}+P(1+i)^{2}+P(1+i)+P$ \\
\hline
\end{tabular}

FIGURE 7: Multiple payments using individual payment approach.

\begin{tabular}{|cll|}
\hline $\begin{array}{c}\text { Number of months after making } \\
\text { deposit }\end{array}$ & Expression for process of compounding & Simplified expression \\
\hline 1 & $F V_{1}=P+P i$ & $F V_{1}=P(1+i)$ \\
2 & $F V_{2}=P(1+i)+P(1+i) i=P(1+i)[1+i]$ & $F V_{2}=P(1+i)^{2}$ \\
3 & $F V_{3}=P(1+i)^{2}+P(1+i)^{2} i=P(1+i)^{2}[1+i]$ & $F V_{3}=P(1+i)^{3}$ \\
4 & $F V_{4}=P(1+i)^{3}+P(1+i)^{3} i=P(1+i)^{3}[1+i]$ & $F V_{4}=P(1+i)^{4}$ \\
\hline
\end{tabular}

FIGURE 5: Compounding of single payment.

\begin{tabular}{|cll|}
\hline $\begin{array}{c}\text { End of } \\
\text { month }\end{array}$ & Expression for gaining interest and making new payment & Strategically factorised expression \\
\hline 1 & $F V_{1}=P$ & $F V_{1}=P$ \\
2 & $F V_{2}=P+P(1+i)$ & $F V_{2}=P[(1+i)+1]$ \\
3 & $F V_{3}=P+P[(1+i)+1](1+i)$ & $F V_{3}=P\left[(1+i)^{2}+(1+i)+1\right]$ \\
4 & $F V_{4}=P+P\left[(1+i)^{2}+(1+i)+1\right](1+i)$ & $F V_{4}=P\left[(1+i)^{3}+(1+i)^{2}+(1+i)+1\right]$ or \\
& & $F V_{4}=P(1+i)^{3}+P(1+i)^{2}+P(1+i)+P$ \\
\hline
\end{tabular}

FIGURE 6: Multiple payments using account balance approach. 
BOX 1: Elimination method to derive formula for future value of an ordinary annuity.

\begin{tabular}{|lll}
\hline 1 & $F V_{n}=$ \\
& $P+P(1+i)+P(1+i)^{2}+P(1+i)^{3}+\ldots+P(1+i)^{n-1}$ & \\
2 & $\begin{array}{l}(1+i) F V_{n}= \\
\\
P(1+i)+P(1+i)^{2}+P(1+i)^{3}+\ldots+P(1+i)^{n-1}+P(1+i)^{n}\end{array}$ \\
3 & Subtracting (1) from (2) produces: & $((1+i)-1) F V_{n}=P(1+i)^{n}-P$ \\
4 & Which leads to: & $F V_{n}=\frac{P\left[(1+i)^{n}-1\right]}{i}$
\end{tabular}

into $n$, as shown in the earlier example. It is worth noting that several textbooks (e.g. Basson et al., 2005; Young, 1993) explicitly link $n$ in the annuities formulae to the number of payments. Yet there is no reason to accept that the meaning of $n$ in line 4 should be any different from its meaning in lines 1,2 and 3.

The ordinary annuity scenario is a critical case here because it shows clearly that the exponent in the formula $(n)$ is not the same as the exponent of the first payment $(n-1)$. In an annuity due scenario this is less clear since $n$ indicates the value of three different elements, namely the number of payments, the number of compoundings of the first payment and the overall number of months in the chosen timeframe.

A further example, involving a complex annuity, is useful to go beyond the special case of simple annuities. Here we deal with a scenario in which the frequency of payments differs from the compounding frequency. Consider the following example:

- We make equal payments, $P$, every 6 months into an account where interest is compounded monthly, and the monthly interest rate is $i$. Payments are made at the end of the month. Assume the first payment is made at the end of the first month, determine how much has accumulated by the end of two years, i.e. the end of the 24 th month.

This scenario gives rise to the following geometric series: $P(1+i)^{23}+P(1+i)^{17}+P(1+i)^{11}+P(1+i)^{5}$. If we reverse the order, we get a geometric series with first term $P(1+i)^{5}$ and common ratio $(1+i)^{6}$. Summing this geometric series we get: $F V_{24}=\frac{P(1+i)^{5}\left[\left((1+i)^{6}\right)^{4}-1\right]}{(1+i)^{6}-i}$. Here we see a more complex common ratio but an exponent of 4 to indicate the four terms that are being added. It is not the case that interest is being compounded only 4 times, even for the first deposit ${ }^{1}$. This example thus reinforces that the exponent in the annuities formula represents the number of payments and not the number of compounding periods.

It is likely that the struggle to accept a shift in the meaning of $n$ is a result of modelling. If the exponent had no contextual meaning in either formula, the problem of the shift in meaning would not exist. But since the initial encounter with the exponent is in terms of the number of compounding periods, it may be disconcerting to conceive of it later as the number of payments. The derivations of the annuities formulae do not provide adequate explanation for a shift in the meaning of $n$. It must simply be accepted as a result of summing a geometric series.

Returning to the discussion of teachers' knowledge, we see again how mathematical and pedagogical aspects are closely intertwined. The lengthy explications above show the detailed mathematical work entailed in decompressing the annuities formulae to re-explore their origins. Ultimately there may be no satisfactory justification for interpreting the exponent as the number of payments when the derivation began with an interpretation of the exponent as the number of compounding periods. Nevertheless, when the compound interest formula and the annuities formulae are used to solve financial mathematics problems, the exponents are interpreted differently. Thus, in order to appreciate students' and learners' conceptions with regard to the exponent, we are obliged to consider the likely origins of these conceptions and difficulties, which leads us to reconsider the underlying mathematics and how this models the growth of payments over time.

\section{Conclusion}

I began this article with a discussion of Shulman's notions of SMK (or CK) and PCK. They are compelling ideas that have been very productive in moving the field forward with respect to research on teachers' knowledge in general and teachers' mathematical knowledge in particular. Whilst they are widely accepted, as Ball et al. (2008) note, they are defined and used in different ways. For this reason they are problematic as analytical constructs and although several attempts have been made to operationalise them (e.g. Ball et al. 2008; Even, 1990; Krauss et al., 2008), the empirical evidence for distinguishing SMK from PCK is still relatively weak. In choosing the term mathematics-for-teaching to encompass an amalgam of mathematical and pedagogical knowledge, I have avoided the SMK-PCK distinction. Furthermore, I have shown how mathematical, pedagogical and contextual knowledge of finance are intertwined in any consideration of teachers' knowledge for teaching annuities. In so doing, I have made an initial contribution to establishing a knowledge base for teachers' knowledge for teaching annuities. It is not simply knowledge of financial mathematics in the way that actuaries or bankers might use it. It contains elements that are fundamentally about how we come to know annuities, how we connect it with existing knowledge of other concepts, such as compound interest, and the importance of knowing the conventions of the banking world.

\section{Acknowledgements}

This work was supported financially by the Thuthuka programme of the National Research Foundation (Grant no: TTK2007050800004). Any opinions, findings and conclusions or recommendations expressed are those of the author and the NRF does not accept any liability. 


\section{Competing interests}

I declare that I have no financial or personal relationships that may have inappropriately influenced me in writing this article.

\section{References}

Adler, J. (2005). Mathematics for teaching: What is it and why is it important that we talk about it? Pythagoras, 62, 2-11.

Adler, J., \& Davis, Z. (2006). Opening another black box: Researching mathematics for teaching in mathematics teacher education. Journal for Research in Mathematics Education, 37(4), 270-296.

Bakker, A., Kent, P., Noss, R., Hoyles, C., \& Bhinder, C. (2006, February). "It's no just magic!" Learning opportunities with spreadsheets in the financial sector. Paper presented at the British Society for Research into Learning Mathematics, University of Warwick, Conventry.

Ball, D., Bass, H., \& Hill, H. (2004, January). Knowing and using mathematical knowledge in teaching: Learning what matters. Paper presented at the 12th Annual Conference of the Southern African Association for Research in Mathematics, Science and Technology Education, Cape Town.

Ball, D., Hill, H., \& Bass, H. (2005). Knowing mathematics for teaching: Who knows mathematics well enough to teach third grade, and how can we decide? mathematics well enough to
American Educator, 29, 14-22.

Ball, D., Thames, M., \& Phelps, G. (2008). Content knowledge for teaching: What makes it special? Journal of Teacher Education, 59(5), 389-407. http://dx.doi. org/10.1177/0022487108324554

Basson, J., Budge, V., Buys, A., Cruywagen, R., Heideman, N., \& Claase, L. (2005). X-kit undergraduate: Maths for business. Cape Town: Pearson.

Dempsey, S. (2003). On the benefits of a mathematical solutions approach to time value of money instruction: Arguments and evidence. Journal of Accounting Education, 21, 239-260. http://dx.doi.org/10.1016/S0748-5751(03)00023-X

Department of Basic Education. (2011). Curriculum and assessment policy statement Grades 10-12 Mathematics. Pretoria: DBE.

Department of Education. (2003). National curriculum statement Grades 10-12 (General) Mathematics. Pretoria: DBE

Eddy, A., \& Swanson, G. (1996). A hierarchy of skills approach to teaching accounting present value. Journal of Accounting Education, 14(1), 123-131. http://dx.doi. org/10.1016/0748-5751(95)00027-5

Even, R. (1990). Subject matter knowledge for teaching and the case of functions. Educational Studies in Mathematics, 21(6), 521-544. http://dx.doi.org/10.1007/ BF00315943

Even, R. (1993). Subject-matter knowledge and pedagogical content knowledge: Prospective secondary teachers and the function concept. Journal for Research in Mathematics Education, 24(2), 94-116. http://dx.doi.org/10.2307/749215

Even, R. (1998). Factors involved in linking representations of functions. Journal of Mathematical Behavior, 17(1), 105-121. http://dx.doi.org/10.1016/S07323123(99)80063-7

Ferrini-Mundy, J., Floden, R., McCrory, R., Burril, G., \& Sandow, D. (2006). A conceptual framework for knowledge for teaching school algebra. East Lansing, MI: Michigan State University.
Fischbein, E. (1999). Intuitions and schemata in mathematical reasoning. Educational Studies in Mathematics, 38, 11-50. http://dx.doi. org/10.1023/A:1003488222875

Gardner, N. (2004). The time value of money: A clarifying and simplifying approach. Journal of College Teaching and Learning, 1(7), 25-30.

Hill, H., Ball, D., \& Schilling, S. (2008). Unpacking pedagogical content knowledge: Conceptualizing and measuring teachers' topic-specific knowledge of students. Journal for Research in Mathematics Education, 39(4), 372-400.

Hill, H., Rowan, B., \& Ball, D. (2005). Effects of teachers' mathematical knowledge for teaching on student achievement American Educational Research Journal, 42(2), 371-406. http://dx.doi.org/10.3102/00028312042002371

Hoyles, C., Noss, R., Kent, P., \& Bakker, A. (2010). Improving mathematics at work: The need for techno-mathematical literacies. Oxon: Routledge.

Huillet, D. (2007). Evolution, through participation in a research group, of Mozambican secondary school teachers' personal relation to limits of functions. Unpublished doctoral dissertation. University of the Witwatersrand functions. Unpublished doct
Johannesburg, South Africa.

Huillet, D. (2009). Mathematics-for-teaching: An anthropological approach and it's elaboration in teacher training. For the Learning of Mathematics, 29(3), 4-10.

Jalbert, T., Jalbert, M., \& Chan, C. (2004). Advances in teaching the time value of money. Journal of College Teaching and Learning, 1(8), 7-12.

Kieran, C. (1981). Concepts associated with the equality symbol. Educational Studies in Mathematics, 12, 317-326. http://dx.doi.org/10.1007/BF00311062

Kitto, A., Fridjhon, P., Glencross, M., Hobday, A., Laridon, P., Newling, P., et al. (1990). Classroom Mathematics: Additional mathematics - Options Std 9 and 10. Johannesburg: Lexicon.

Krauss, S., Baumert, J., \& Blum, W. (2008). Secondary mathematics teachers' pedagogical content knowledge and content knowledge: Validation of the COACTIV constructs. ZDM: The International Journal on Mathematics Education, 40, 873-892. http://dx.doi.org/10.1007/s11858-008-0141-9

Krauss, S., Brunner, M., Kunter, M., Baumert, J., Blum, W., Neubrand, M. et al. (2008). Pedagogical content knowledge and content knowledge of secondary mathematics teachers. Journal of Educational Psychology, 100(3), 716-725. $\mathrm{http}: / / \mathrm{dx}$.doi.org/10.1037/0022-0663.100.3.716

Pournara, C. (2012). Does the compound interest formula give us the "real" answer? Learning and Teaching Mathematics, 12, 24-26.

Pournara, C. (2013a). Mathematics-for-teaching in pre-service secondary mathematics teacher education: The case of financial mathematics. Unpublished doctoral dissertation. University of Witwatersrand, Johannesburg, South Africa.

Pournara, C. (2013b). Teachers' knowledge for teaching compound interest. Pythagoras, 34(2), 1-10. http://dx.doi.org/10.4102/pythagoras.v34i2.238

Ruthven, K. (2011). Conceptualising mathematical knowledge in teaching. In T. Rowland, \& K. Ruthven (Eds.), Mathematical knowledge in teaching (pp. 83-96). New York, NY: Springer. http://dx.doi.org/10.1007/978-90-481-9766-8_6

Shulman, L. (1986). Those who understand: Knowledge growth in teaching. Educational Researcher, 15(2), 4-14. http://dx.doi. org/10.3102/0013189X015002004

Shulman, L. (1987). Knowledge and teaching: Foundations of the new reform. Harvard Educational Review, 57(1), 1-22.

Young, D. (1993). Financial mathematics: A computational approach. Cape Town 